\title{
CRISIS DE RÉGIMEN, REFUNDACIÓN Y/O RUPTURA
}

\section{Jaime Pastor \\ Universidad Nacional de Educación a Distancia (UNED)}

RESUMEN: La crisis de régimen a la que estamos asistiendo obliga a recordar sus orígenes en la Transición política y en el posterior proceso de integración en Europa y en la eurozona. En ese marco se analiza la evolución de las relaciones entre la ciudadanía y las distintas instituciones del régimen para adentrarse en los efectos generados por la crisis sistémica global y europea a partir de 2008, así como en la relevancia del ciclo de protestas abierto con el acontecimiento del 15 de mayo de 2011. La crisis del Estado autonómico y la cuestión catalana también son tenidas en cuenta. Se concluye constatando un vaciamiento creciente del Estado social, democrático y de derecho y, con él, del régimen y del proyecto europeo para apuntar finalmente algunas hipótesis sobre las alternativas en términos de refundación o ruptura que parecen desplegarse en la actualidad.

Palabras clave: democracia, legitimidad, partidos políticos, movimientos sociales.

RESUM: La crisi de règim a què estem assistint obliga a recordar els seus orígens en la transició política i en el posterior procés d'integració a Europa i a l'eurozona. En aquest marc s'analitza l'evolució de les relacions entre la ciutadania i les distintes institucions del règim per a endinsar-se en els efectes generats per la crisi sistèmica global i europea a partir de 2008, així com en la rellevància del cicle de protestes obert amb l'esdeveniment del 15 de maig de 2011. La crisi de l'Estat autonòmic i la qüestió catalana també són tingudes 
en compte. Es conclou constatant un buidament creixent de l'Estat social, democràtic i de dret $\mathrm{i}$, amb aquest, del règim i del projecte europeu per a apuntar finalment algunes hipòtesis sobre les alternatives en termes de refundació o ruptura que pareixen desplegar-se en l'actualitat.

Paraules clau: democràcia, legitimitat, partits, moviments socials.

ABSTRACT: The regime crisis we are currently witnessing obliges us to recall its origins in the political transition and the subsequent process of integration in Europe and the eurozone. In this context we analyse the evolution of relations between citizens and the various institutions of the regime to explore the effects of the global and European systemic crisis that began in 2008, and the relevance of the cycle of protests initiated with the events of 15 May, 2011. The crisis of the autonomous State and the Catalan question are also considered. The paper concludes by noting an increasing depletion of the social, democratic and legal State, and with that, of the regime and the European project, and finally puts forward some hypotheses on alternatives in terms of refounding or break-up that appear to be spreading today.

KEYWORDs: democracy, legitimacy, parties, social movements.

E ya un lugar común desde muy diversos sectores ideológicos de opinión considerar que nos encontramos en una crisis del régimen político que se fue conformando a partir de los Pactos de la Moncloa y la Ley de Amnistía de octubre de 1977 y de la Constitución escrita de 1978. Una ley fundamental que luego se vería complementada con las exigencias derivadas del proceso de integración plena en el bloque occidental geoeconómico y militar y, ya a partir del Tratado de Maastricht de 1992, sufriría una progresiva involución en un sentido neoliberal hasta llegar a la reforma exprés del artículo 135 en pleno verano de 2011; internamente, los distintos estatutos de autonomía irían formando parte del bloque constitucional, pero siempre bajo la vigilancia de 
una tercera cámara, el Tribunal Constitucional, con el fin de que no cuestionaran la unidad del Estado... y del mercado.

Esta Constitución material ha ido sustentando un régimen que hoy parece agotar su funcionalidad al servicio de un capitalismo español en quiebra. Sin embargo, existen distintas percepciones de cómo afecta esa crisis a las distintas instituciones, cuál es el grado de deslegitimación que están sufriendo $\mathrm{y}$, sobre todo, cuáles son las vías de salida a la misma en el momento actual.

\section{De la Transición a la crisis sistémica}

No me extenderé mucho en recordar las enormes limitaciones que tuvo el proceso de la transición política española Sí creo necesario destacar que la ausencia de una efectiva ruptura con la dictadura que condujera a un proceso constituyente libre de ataduras no impidió la aprobación de la nueva Constitución en el referéndum de diciembre de 1978 y, con ella, la puesta en pie de un régimen monárquico parlamentario, pero con unas particularidades antidemocráticas que irían poniéndose en evidencia a lo largo de los decenios siguientes, si bien en aquel momento sólo se vieron impugnadas - en las urnas, en la calle y mediante la expresión violenta de ETA- en Euskadi. Porque el hecho de que no hubiera el ajuste de cuentas necesario con el franquismo y su legado en sus distintos órdenes - en el plano simbólico, en el aparato coercitivo y judicial o en el de las relaciones privilegiadas con la Iglesia católica - condujo desde el principio a una democracia tutelada, basada en el turnismo entre los dos grandes partidos al servicio del mismo bloque de poder, progresivamente ampliado con la nueva clase media ascendente; en ese marco general se desarrolló una cultura de cinismo político - lo que ahora se conoce como «cultura de la Transición»- cuyos costes ya empezamos a comprobarlos muy pronto con el llamado «desencanto».

En efecto, acontecimientos como el $23 \mathrm{~F}$ de 1981, con la imagen salvadora de Juan Carlos I, el proceso de relativa descentralización política, la llegada al gobierno en 1982 de jóvenes nacionalistas españoles encabezados por Felipe González y la integración en la Comunidad Económica Europea y la OTAN en 1986 contribuyeron a una relativa estabilización del régimen y a dar algunos pasos desde el Estado asistencial franquista hacia otro de un 
modesto Estado de «bienestar» que, sin negar sus mejoras, compartía las limitaciones estructurales de ese modelo (Cabo, 2012), más patentes en nuestro caso que en otros lares. Muy pronto, además, tuvo que hacerse compatible con un europeísmo neoliberal en el que el capitalismo español entraba en un lugar subalterno, pero con expectativas de lograr una legitimación social entre sectores populares ilusionados en acceder a Europa y, con ella, a la nueva sociedad de propietarios y consumidores. Una tarea que, tras la debacle de la Unión de Centro Democrático (UCD), asumiría el social-liberalismo del PSOE, más funcional en ese contexto para convertirse en pieza fundamental de legitimación del régimen ante los y las de abajo a lo largo de 14 años, mientras se iba produciendo un proceso de recomposición de la derecha, finalmente consumada con la refundación de Alianza Popular en Partido Popular y su llegada al gobierno en 1996.

Durante todo este tiempo sólo el conflicto vasco —incluida la versión militarista de ETA — se ha mantenido como la principal llamada de atención permanente ante el déficit estructural de ese régimen, ya que otras manifestaciones del autoritarismo neoliberal (y de «guerra sucia», como los GAL) e incluso de corrupción (con una larga lista que ha ido afectando al plural arco parlamentario) no llegaron a tener costes relevantes para sus responsables en el plano electoral, debido precisamente al arraigo del bipartidismo imperfecto gracias a la cultura del cinismo político ya recordada y a la ilusión popular en poder beneficiarse del efecto riqueza, reforzado tras la puesta en marcha del euro. Ha habido que esperar a que en 2008 estallara la burbuja inmobiliaria, en medio de la crisis financiera y de la eurozona, para que el sentimiento de agravio comparativo frente a los responsables de esa múltiple crisis, a su vez afectados por escándalos de corrupción que han ido alcanzando a los distintos pilares del régimen, transformara el malestar social en protesta masiva a través de la ocupación del espacio público. Por eso es ahora cuando las especificidades de un régimen surgido de la reforma de la dictadura aparecen más en evidencia, mientras que los rasgos que tienen que ver con sus virtudes (Estado social y de derecho) quedan cada vez más vaciados de contenido, sobre todo, como ya se ha recordado, tras la reforma exprés del artículo 135 de la Constitución que convierte en prioridad absoluta el pago de la deuda y el cumplimiento del déficit fijado en la eurozona. 
Con todo, conviene recordar que antes incluso de 2008 ya vimos en la primera legislatura presidida por Rodríguez Zapatero la irrupción de un movimiento cada vez más relevante a favor de la recuperación de la memoria histórica y de verdad, justicia y reparación para las víctimas del franquismo. El eco obtenido por sus colectivos promotores en su denuncia de la ausencia de la justicia transicional que caracterizó a la caída del fascismo en otros países ayudó a poner de relieve el enorme coste político que supuso la aprobación de la Ley de Amnistía de octubre de 1977 y, con ella la ausencia de un ajuste de cuentas con la dictadura. El limitado reflejo de esa campaña en la conocida como Ley de Memoria Histórica y las trabas posteriores del poder judicial — mostrando así, como en el caso del PP, el lastre franquista que arrastran muchos de sus miembros (Sáez, 2010; Olivas, 2012) - a la investigación sobre los crímenes del franquismo no han impedido la continuidad e incluso mayor audiencia de este movimiento, con mayor motivo cuando han conseguido que una jueza argentina admita la tramitación de una querella contra el franquismo y salgan a la luz pública informaciones tan reveladoras de la supervivencia de la cultura represiva franquista como la función que ejerce como formador de miembros del aparato policial del Estado desde hace tiempo el asesino de Yolanda González, Emilio Hellín.

También bajo el gobierno de Rodríguez Zapatero se abrió una pequeña ventana de oportunidad para plantear en la agenda política la superación de los límites del Estado autonómico, sobre todo en el caso catalán, pero finalmente el nacionalismo constitucional español (PP, PSOE y, finalmente, el Tribunal Constitucional) se convirtió en una barrera infranqueable para permitir una lectura moderadamente federalizante de la Constitución española. No obstante, esto no significó una paralización de los movimientos a favor del reconocimiento de la realidad plurinacional del Estado sino todo lo contrario, como estamos viendo.

Justamente en el proceso de relevo del gobierno de Rodríguez Zapatero por el de Mariano Rajoy, y en el marco del estallido de la mezcla explosiva de distintas crisis interdependientes ya mencionada, hemos podido ver la irrupción de nuevos actores colectivos que tienen en el movimiento $15 \mathrm{M}$ y las «mareas» las manifestaciones más visibles del paso de la desafección y la indignación ciudadanas a la protesta activa frente a la «dictadura de los mer- 
cados». Es precisamente ésta, representada por la troika y el Estado alemán, hegemónico en la eurozona, la que está presentándose como un soberano supraestatal con cada vez más voluntad de poder sobre los pueblos de Europa del sur.

Nos encontramos, por tanto, en un contexto en el que, por un lado, avanza un proceso de desconstitucionalización desde arriba mientras que, por otro, aumenta la voluntad destituyente de este régimen desde los nuevos movimientos sociales protagonistas de las principales protestas en el nuevo ciclo iniciado el 15 de mayo de 2011.

Esa crisis es, sobre todo, la de la formulación del «Estado social, democrático y de derecho» que aparece en la Constitución. En lo social porque si bien vienen de lejos las políticas neoliberales, desde 2008 estamos conociendo una aceleración enorme del desmantelamiento de conquistas y derechos sociales a través del desempleo masivo, de los recortes del salario - directo, indirecto y diferido - y de privatizaciones varias en el sector público, generando una desigualdad y una polarización social que no dejan de aumentar y que en nuestro caso se encuentran entre las mayores de la eurozona. En lo democrático porque el creciente vaciamiento de competencias prácticas del parlamento español y el recurso permanente al decreto-ley, la contradicción entre las promesas electorales y la subordinación a los dictados de la troika por parte de los partidos en el gobierno, junto a la percepción de la corrupción como un rasgo sistémico y no meramente superficial, están generando una pérdida de legitimidad de la democracia liberal representativa a pasos acelerados. En el plano del garantismo jurídico porque, junto al vaciamiento de los derechos sociales reconocidos en la Constitución, si bien desde hace tiempo — con la excusa del «terrorismo vasco»— se ha ido consolidando una legislación y una jurisdicción de excepción (la Audiencia Nacional) y, con ella, un derecho penal del enemigo, vemos ahora cómo se quiere extender éste a diferentes formas de protesta y de desobediencia civil, siendo algunas de sus últimas expresiones el intento - finalmente fallido gracias incluso a sentencias judiciales - de criminalización de los escraches y, sobre todo, el actual proyecto de Ley de Seguridad Ciudadana.

En realidad, esa crisis afecta en mayor o menor grado a muchos Estados del ámbito de la eurozona, especialmente de los países del sur, en donde la 
deudocracia pretende imponerse por encima incluso de la opinión de los tribunales constitucionales respectivos. También en ellos estamos viendo otros rasgos comunes con el caso español: en particular, la crisis de centralidad de los dos grandes partidos y el ascenso de otras opciones electorales, tanto por la izquierda como por la derecha y transversalmente, en medio de un clima general de rechazo a la política institucional y sistémica, de sentimiento anti-partidos y de tendencia a extenderse la figura de «votante volátil», más influenciable por divisorias a corto plazo (Mair, 2007). Una crisis que tiene que ver, obviamente, con la de lo que fue su corolario bajo los Estados menguantes del bienestar: el neocorporativismo basado en la concertación entre sindicatos, patronal y gobierno, sustituido ahora por una política del shock que, además de seguir debilitando el poder estructural de la clase obrera, busca ahora desprenderse del poder asociativo de sectores asalariados que, aun bajo su forma burocratizada y pactista, representan los sindicatos mayoritarios.

En resumen, en los países del sur de la eurozona estamos asistiendo a una transición histórica en la que se está poniendo en pie una nueva gobernanza neoliberal que, aprovechando la crisis de los partidos políticos, aspira a sustituir la que permitía cierto margen de deliberación y decisión en las instituciones representativas por otra de tipo tecnocrático-autoritario, a-democrática. Ésta se limitaría a exigir la mera ratificación formal de sus dictados en esas instituciones buscando así asegurarse la obediencia de la ciudadanía (de la que quieren excluir a la población trabajadora inmigrante que no dé prueba de identificación con los «valores nacionales») a «las únicas políticas posibles» impuestas por la troika. No faltan, por cierto, ideólogos para lo que pretende ser una alternativa a la crisis del paradigma demo-liberal, siendo uno de los más destacados Pierre Rosanvallon, admirado aquí desde distintos sectores y justamente criticado por otros (Noguera, 2012: 121-128).

El gran problema que tiene este nuevo modelo es que está subordinado a una deudocracia y a unas políticas austeritarias de duración indefinida, al servicio de los acreedores y del salvamento del sistema financiero y sin credibilidad alguna para mantener la ilusión entre los y las de abajo de que «la luz al final del túnel» está cerca. Con ese panorama, la legitimación por consentimiento de sus políticas por los pueblos puede llegar a ser cada vez más precaria a medida que se van dando pasos a un ritmo acelerado en la nue- 
va fase de acumulación capitalista bajo sus distintas formas. Con unas elites autistas, por un lado, y una desafección ciudadana creciente, por otro, la crisis institucional permanente y los riesgos de des-integración social y sistémica parece que van a ser la regla en los próximos tiempos. Las situaciones en las que se encuentran Grecia e Italia (con el fracaso estrepitoso del intento de reelegir al tecnócrata Mario Monti, el ascenso del M5S y la actual reedición de la vieja forma de hacer política), por no hablar de lo que está ocurriendo en los países del Este europeo, anuncian un efecto dominó de crisis de regímenes dentro de la eurozona, procesos que en ausencia de alternativas desde la izquierda son caldo de cultivo para el ascenso de la extrema derecha y de populismos transversales.

\section{Crisis del Estado autonómico, de la monarquía y del bipartidismo «imperfecto»}

Lo específico en el caso español estaría en que a esos factores se suman los relacionados con pilares hasta ahora básicos para garantizar la estabilidad del régimen. Uno y fundamental es el que tiene que ver con la relación nacionalismo español-nacionalismos periféricos, agravada tanto por el fundamentalismo constitucional de los dos partidos de ámbito estatal y el Tribunal Constitucional como por los efectos de la crisis de la deuda y los agravios comparativos entre comunidades autónomas en torno al sistema de financiación autonómica. El otro es el relacionado con la monarquía, cuya impopularidad ya va más allá de las zonas vasca o catalana gracias a los escándalos de corrupción que afectan a la Casa Real.

La crisis del Estado autonómico supone una quiebra clave en el régimen vigente porque demuestra el fracaso de la apuesta que el nacionalismo español dominante hizo en la Transición. La convicción de que se podría imponer una concepción esencialista de la nación española como única nación, frente a la realidad plurinacional existente, a cambio de un proceso de descentralización política y del reconocimiento de algunos hechos diferenciales, confiando en que la integración europea permitiría cumplir el viejo sueño de Ortega y Gasset de que Europa sería la solución al problema español, ha terminado 
viéndose desmentida por la Europa-pesadilla en la que ahora estamos y por el desafío soberanista catalán.

Por eso hoy vemos un nacionalismo español más a la defensiva que nunca frente a un independentismo catalán que, tras el fracaso del Estatut y frente a las obligaciones derivadas del déficit fiscal, amenaza con desbordar a Convergència i Unió mediante la reivindicación de un derecho a decidir que cuenta con un amplio consenso social, incluso dentro del Partit Socialista de Catalunya. La decisión del Parlament catalán de convocar la consulta el 9 de noviembre en torno a dos preguntas que abren la puerta a una opción independentista ha sido una nueva prueba de fuerzas entre fundamentalismo constitucional y legitimación democrática que está lejos de verse resuelta, pese a su suspensión por el Tribunal Constitucional.

Es aquí donde está más abiertamente en juego la legitimidad del régimen e incluso del Estado como tal, ya que están en cuestión las fronteras territoriales en las que se asientan y el demos en el que se basan, después de haberse negado en distintas ocasiones a reconocer distintos demoi que pudieran pactar entre sí un nuevo tipo de relación, ya fuera federal o confederal, como ya vimos anteriormente con el rechazo al Plan Ibarretxe.

El problema está en que los efectos de la crisis de la deuda - y de los agravios comparativos que la acompañan también entre territorios- favorecen un discurso recentralizador del pP en el resto del Estado que cuenta con el apoyo de una parte importante de la opinión pública española, mientras que en Catalunya refuerza la búsqueda de una salida propia. Por eso no va a ser fácil convertir la brecha que en la legitimidad del régimen puede suponer la disposición a celebrar la consulta independentista en ventana de oportunidad para no sólo apoyar su derecho a decidir sino también para extender esa reivindicación a otras cuestiones como el pago o no pago de la deuda ilegítima.

En cuanto a lo relacionado con la monarquía, su función simbólica de legitimación del tránsito de la vieja legalidad franquista a la nueva legalidad de una democracia de baja intensidad, así como la de garante de la unidady permanencia del Estado, parecían aseguradas tras la leyenda forjada en torno al golpe del 23F y la relativa estabilidad política vivida durante largo tiempo. Sin embargo, la irrupción del movimiento por la recuperación de la memoria histórica $-\mathrm{y}$ con ella del republicanismo - primero y, luego, la progresiva 
superación del tabú en los medios de comunicación sobre el enriquecimiento público - y los sucesivos casos de corrupción que acompañan a él y a su familia - de un monarca cuya persona es, según la Constitución, «inviolable» $\mathrm{y}$ «no sujeta a responsabilidad», han hecho caer en picado su presunta popularidad. Hasta en las elites dominantes ha aumentado la incertidumbre sobre cómo asegurar la continuidad de la monarquía y ha obligado a adelantar la sucesión de Juan Carlos I por Felipe VI tras los resultados de las elecciones europeas de este año. Con los escándalos de los que sigue siendo protagonista la familia en las portadas de los grandes medios de comunicación occidentales, ni siquiera su papel al servicio de la «marca España» parece hoy ser útil, más allá de sus inmejorables relaciones con regímenes despóticos como los del golfo arábigo. La hipótesis de que en un escenario de crisis de régimen la polarización monarquía-república, planteada no sólo desde la izquierda sino también desde algunos sectores de la derecha extrema, pase a primer plano, no es en absoluto descabellada.

Pero es que, además, la crisis que atraviesan los dos grandes partidos de ámbito estatal también muestra síntomas de agravación difícilmente reversibles, como se puede comprobar en los últimos sondeos. El dato de que sumando ambas fuerzas políticas no lleguen al 50\%, como ya ha ocurrido en las elecciones europeas, revela hasta qué punto se está acelerando la profundización de esa crisis como resultado combinado de los recortes sociales protagonizados por uno y otro partido, los escándalos de corrupción que los afectan y la percepción creciente del autismo que caracteriza a sus oligarquías partidarias.

Esto es más patente en el caso del partido que hoy gobierna, ya que la contradicción entre sus promesas electorales y las políticas que está adoptando parecen estar provocando un desgaste progresivo en una parte al menos de sus votantes, especialmente cuando se producen ataques a derechos fundamentales como la sanidad y las pensiones o ante escándalos como el de las «preferentes». Por no hablar de las consecuencias de todo tipo que puede tener el caso Bárcenas como prueba mayúscula de la prolongada financiación 
ilegal de este partido desde sus mismos orígenes en Alianza Popular ${ }^{1} \mathrm{o}$, más recientemente, la Operación Púnica.

No obstante, como partido de gobierno, no podemos menospreciar el margen de maniobra que todavía tiene, gracias a su mayoría absoluta parlamentaria y en un número importante de Comunidades Autónomas y Ayuntamientos, al control de los grandes medios de «formación de masas» (como le gustaba denominarlos a Agustín García Calvo) estatales y privados y en el marco de la todavía hegemónica racionalidad neoliberal (Dardot y Laval, 2013) y del arraigo de la «Cultura de la Transición» en las viejas generaciones. Estos recursos pueden ayudarle a desarrollar tácticas compensatorias de la ilegitimidad de sus políticas antisociales: bien sea con la excusa de la inevitabilidad de esas políticas (y echando la culpa a Bruselas y al BCE, como hace Rajoy cuando declara «No podemos elegir [...], no tenemos libertad»), por la ausencia de alternativas desde la principal fuerza — aún — de oposición y los grandes sindicatos, mediante los intentos de desviar la atención del electorado introduciendo en la agenda política otras cuestiones «como el aborto, ${ }^{2}$ la batalla lingüística en Catalunya, la seguridad ciudadana y la xenofobia, el deporte «nacional»—o, simplemente, graduando y segmentando los ataques a los derechos sociales y servicios públicos con el fin de evitar la confluencia de las luchas y poder reprimir mejor las formas más transgresoras de desobediencia civil, como hemos visto con los escraches.

En este sentido, no deberíamos deducir de la crisis de legitimidad de ejercicio del gobierno que ya estemos en condiciones para transformarla en una deslegitimación suficiente desde abajo para forzar su dimisión o su destitución a la manera sudamericana. Es, por tanto, la vía electoral la que aparece como la más probable, sobre todo tras el reflujo que afecta a la ola de mo-

1. Un escándalo que, junto a los de la Casa Real, ha llevado a la Comisión Europea a elaborar un Informe Interno en el que reconoce que «los españoles han perdido la confianza en la clase política» y considera que «la corrupción es otro lastre para la confianza de los inversores en España»; no sorprende ya que hasta desde el Real Instituto Elcano se exprese el temor de que una «prima de riesgo política» en subida constante contribuya a un nuevo aumento de la prima de riesgo económica («Alerta sobre la corrupción en España», El País, 8/2/13, 4).

2. Si bien, como hemos viso, el anteproyecto de ley que se iba a presentar se ha convertido en un bumerán que ha conducido finalmente a su retirada y a la dimisión del ministro de Justicia, Gallardón. 
vilizaciones iniciada por el $15 \mathrm{M}$ y del bloqueo institucional con el que ha chocado.

En cuanto al PSOE, el golpe de timón que dio Rodríguez Zapatero en mayo de 2010 fue una cruda manifestación de su rendición ante los dictados de los mercados y, con ella, el reconocimiento de la imposibilidad de hacer compatibles las políticas neoliberales con el mantenimiento de algunas de las conquistas sociales que, resultado de duras luchas, fueron legalizadas en el pasado. Desde entonces, a la crisis de proyecto se suman una crisis agónica de liderazgo y una fractura nacional-territorial interna (sobre todo, con el PSC) que no parecen encontrar solución a corto plazo.

¿Significa esto que este partido va a entrar en un proceso de pasokización? Es difícil predecirlo, pero tanto la pérdida de credibilidad que está teniendo como alternancia en el gobierno - al debilitarse cada vez más su frente catalán - como el riesgo de que incluso un modesto giro a la izquierda beneficie más a Izquierda Unida (IU) — como parece estar ocurriendo en Andalucía- y a la nueva fuerza ascendente, Podemos, unidos al retraso en superar al menos la crisis de liderazgo, apuntan un claro retroceso, aunque no llegue a descender tanto como en el caso griego.

Si a la crisis de ambos sumamos la de ciu, principal aliada cuando aquéllos no contaban con mayoría absoluta en el Parlamento español, frustrada en su propuesta de pacto fiscal, en notable desgaste por sus recortes y sus escándalos de corrupción (caso Pujol, sobre todo) y amenazada por el ascenso de Esquerra Republicana de Catalunya, parece ya improbable que pueda garantizar una repetición de los pactos de legislatura del pasado.

\section{Una segunda transición (im)posible}

Las perspectivas que se abren son, por tanto, de agravación de la crisis de gobierno y de régimen y de eso parece ser consciente el bloque de poder dominante, dentro del cual se empiezan a observar iniciativas de cara incluso a una refundación o segunda transición que permitiera emprender una serie de reformas capaces de bloquear el ascenso de fuerzas rupturistas no sólo en Catalunya y en Euskal Herria, sino también a escala estatal, como ocurre ahora con Podemos. La principal dificultad con que choca este proyecto está 
en que, además de que tendría que ser promovido por la misma clase política ampliamente rechazada por la población, ${ }^{3}$ los «brotes verdes» de recuperación de beneficios económicos por parte de «los de arriba» van acompañados por una creciente agravación de la desigualdad social y el continuo aumento de la deuda pública. Es previsible, por tanto, que prosiga la fuerte presión desde la troika y el Gobierno alemán para continuar aplicando nuevos recortes que restringirán, más si cabe, la capacidad de las elites para legitimar esa nueva operación lampedusiana.

Por eso, aun siendo conscientes de las limitaciones que encuentran los bloques sociopolíticos en formación, ${ }^{4}$ no parece que las promesas de una reforma constitucional sean ya suficientes para neutralizar las presiones a favor de una ruptura democrática que a través de la movilización social y el ascenso electoral de Podemos — desde mayo de 2014 - están poniéndose de actualidad. No cabe descartar, por tanto, que paralelamente al ciclo electoral de 2015 vayan reforzándose nuevos poderes sociales y electorales (Pisarello, 2013) que desborden los marcos del régimen actual y conduzcan a verdaderos procesos constituyentes a escala nacional, estatal y, al menos, entre los pueblos del sur en lucha por su soberanía frente a la deudocracia y sus fieles servidores en las distintas naciones y Estados.

3. Eso mismo reconocía El País en su edición del 10 de febrero de 2013, al presentar su propuesta de decálogo bajo el título «Cómo reconstruir el futuro», cuando expresaba su pesimismo ante la contradicción que supone que esa tarea reformista sea asumida por unos líderes políticos con una creciente «impopularidad y falta de credibilidad ante los ciudadanos»; por eso expresaba también su temor de que, de no llevarse a cabo ese proceso, «el régimen emanado de la Constitución de 1978 correrá innecesarios riesgos en el próximo futuro». Ese documento incluía un conjunto de reformas políticas y sociales, entre ellas: la financiación transparente de los partidos y de la Corona, listas abiertas y sistema electoral proporcional, un Estado federal y una reforma de la Constitución; se puede consultar el texto completo en $<\underline{\mathrm{http} \text { ://elpais.com/ }}$ elpais/2013/02/09/opinion/1360442309 070963.html>.

4. A propósito de esto considero oportunas muchas de las reflexiones que aportan Joaquín Miras y Joan Tafalla (2013), especialmente las relacionadas con su apelación a que «no hay cambio real de sociedad sin cambio radical de cultura» y a los riesgos de un proceso constituyente sin el pueblo soberano como protagonista. 


\section{Referencias}

CABO, A. DE (2012): «El fracaso del constitucionalismo social y la necesidad de un nuevo constitucionalismo». En VvaA (2012): Por una Asamblea Constituyente, Sequitur, Madrid.

Dardot, P. y Ch. Laval (2013): La nueva razón del mundo, Gedisa, Barcelona.

MaIR, P. (2007): «¿Gobernar el vacío? El proceso de vaciado de las democracias occidentales», New Left Review, 42, 22-46.

Miras, J. y J. Tafalla (2013): «Una vez más, la izquierda como problema», Sinpermiso, 24, marzo, <http://www.sinpermiso.info/articulos/ficheros/miras.pdf $>$ [consulta: $2 / 11 / 14$ ].

Noguera, A. (2012): Utopía y poder constituyente. Sequitur, Madrid.

Olivas, A. (2012): «Justicia y crisis: ¿Quiénes son los jueces?», Viento Sur, 125, 87-95.

Pisarello, G. (2013): «Reino de España: perspectivas de un proceso constituyente", Sinpermiso, 17 de marzo, $<\underline{\text { http://www.sinpermiso.info/ }}$ textos/index.php?id=5787> [consulta: $2 / 11 / 14$ ].

Sáez, R. (2010): «Los jueces y el aprendizaje de la impunidad», Mientras tanto, 114, 41-72. 